\title{
O IMPACTO DA REFORMA TRABALHISTA NO ACESSO À JUSTIÇA: UMA ANÁLISE ECONÔMICA DA LITIGÂNCIA
}

\author{
James Edgar Smith ${ }^{1}$ \\ Fábio Túlio Barroso ${ }^{* * *}$
}

RESUMO: Este estudo tem por objetivo analisar a nova sistemática de acesso à Justiça do Trabalho introduzida pela Lei n. 13.467/2017, no pertinente à opção legislativa de aumentar os custos para o trabalhador acionar o Judiciário. Visando a redução da alta taxa de litigância verificada, o legislador limitou-se a atacar parte do problema, deixando de enfrentar outros fatores que podem influenciar nos níveis de litigância do sistema, consoante modelo metodológico da Análise Econômica da Litigância (AEL). Como resultado, o acesso mais oneroso ao trabalhador poderá prejudicar a exigibilidade das normas trabalhista e seu cumprimento espontâneo, objetivos primordiais das normas de processo.

PALAVRAS-CHAVE: Reforma Trabalhista; Acesso à Justiça do Trabalho; Análise Econômica da Litigância; Custos de oportunidade; Mudanças marginais

\section{THE IMPACT OF LABOR REFORM IN ACCESS TO BRAZILIAN LABOR JUSTICE: AN ECONOMIC ANALYSIS OF LITIGATION}

\begin{abstract}
This paper aims to analyze the new systematic of access to Brazilian Labor Justice introduced by Law n. 13.467/2017, in consequence of a legislative option to rising the expenses of plaintiff bringing suit to the Court. In way to reduce the high tax of litigation, the legislator strikes part of the problem, leaving intact other factors that may influence the level of litigation in the system, according to the model of Economic Analysis of Litigation (EAL). In result, the more expensive cost of suit may prejudice the labor law enforcement, primary objective of procedural rules.
\end{abstract}

KEYWORDS: Labor Reform; Access to Brazilian Labor Justice; Economic Analysis of Litigation; Opportunity cost; Marginal changes

\footnotetext{
1 Mestrando em Direito pela Universidade Católica de Pernambuco (UNICAP). Endereços: Rua Francisco da Cunha, 660, apto 1202 - Boa Viagem, Recife-PE - 51020-041 e james.2020603110@unicap.br

** Advogado, Professor da Universidade Católica de Pernambuco e da Universidade Federal de Pernambuco. Pós-doutor em Direito pela Universidad de Granada, Espanha. Endereços: Rua do Príncipe, 526 - Boa Vista, Recife - PE - 50050-900 e fabio.tulio@ unicap.br
} 


\section{INTRODUÇÃO}

A Lei n. 13.467/2017, denominada de Reforma Trabalhista, alterou profundamente as normas trabalhistas, tanto no seu aspecto material, quanto no âmbito processual e em especial de acesso à Justiça do Trabalho, ocasionando um aumento nos custos de acionar o Judiciário pelo trabalhador-reclamante. O legislador reformista atuou no sentido de buscar a redução da alta taxa de litigância verificada, arvorando-se na possibilidade de editar normas processuais com o fim de desincentivar a litigiosidade. Trata-se de política legislativa que encontra sustentação na Análise Econômica da Litigância (AEL).

Os modelos resultantes da interação entre a teoria econômica e a ciência do direito processual identificaram alguns fatores que podem influenciar os níveis de litigância em determinado sistema, bem como os meios possíveis para retorná-los a patamares desejáveis, quer se trate de hipótese de litígios insuficientes ou em excesso. Para fins de reduzir a taxa de congestionamento no judiciário trabalhista, a Lei n. 13.467/2017 amparou-se quase que exclusivamente na política de aumentar os custos para o ingresso de ações trabalhistas.

O problema objeto deste trabalho gira em torno da seguinte pergunta de partida: é adequado que o desincentivo à litigiosidade na Justiça do Trabalho se dê exclusivamente por meio do aumento dos custos econômicos de demandar no primeiro grau de jurisdição?

A resposta a essa indagação pressupõe incursão sobre temas correlatos como a Análise Econômica do Direito (AED), o estudo descritivo do comportamento na tomada de decisões (AED positiva), a avaliação prescritiva da regulação do comportamento (AED normativa), a diferença entre custos privados e custos sociais do processo, o funcionamento das técnicas de incentivo e desincentivo existentes nas normas jurídicas e como essa estrutura pode influenciar no cumprimento dos contratos e nas escolhas dos agentes entre litigar ou renunciar a seus direitos e entre recorrer ou conformar-se com a sentença judicial ou ainda o desincentivo ao cumprimento das normas fundamentais de trabalho por parte dos empregadores.

Nesse contexto, o problema de pesquisa será testado mediante a seguinte hipótese: o aumento nos custos de litigar na Justiça do Trabalho, sem considerar outros fatores apontados pela Análise Econômica da Litigância, servirá como estímulo ao descumprimento do contrato de trabalho por parte do empregador.

O texto pretende expor uma análise multifatorial acerca das possíveis medidas para redução da litigiosidade nas relações de trabalho, analisando os impactos da reforma que se 
pautou no particular quase que exclusivamente no aumento dos custos econômicos de demandar em primeiro grau de jurisdição. Desta feita, será adotada no trabalho a metodologia dedutiva, com apoio em pesquisa bibliográfica, artigos científicos e dados estatísticos do Conselho Nacional de Justiça (CNJ) e do C. Tribunal Superior do Trabalho (TST).

\section{DIREITO, ECONOMIA E PROCESSO}

O Direito se constitui em uma dentre várias técnicas existentes de controle do comportamento social. A coexistência harmoniosa entre as pessoas pressupõe o estabelecimento de regras mínimas de boa convivência, a serem seguidas em sociedade. Essas normas de conduta são estabelecidas de forma prévia pela legislação, por meio da qual o Estado elege os valores mediante os quais o comportamento das pessoas será regulado em cada momento da história.

Para tanto, são utilizadas as categoriais jurídicas do proibido, do obrigatório, do permitido, do lícito e do ilícito, em obediência ao formalismo jurídico presente na concepção moderna de Direito. Ao agir dessa forma, nas palavras de Cândido R. Dinamarco, o Estado está "[...] positivando o seu poder, no sentido de evitar as condutas desagregadoras, estimular as agregadoras, distribuir bens entre as pessoas - e, por essas formas, criar o clima favorável à paz entre os homens, eliminando as insatisfações.” (2008, p. 189-190).

De outra parte, o Direito se caracteriza pelo fato de que os comportamentos previstos nas normas jurídicas podem ser exigidos, quando violado ou ameaçado interesses juridicamente protegidos. Assim, o comportamento estabelecido previamente na norma pode ser assegurado por intermédio do Poder Judiciário, regulando comportamentos ex post. A tutela de direitos eficaz compreende sua previsão no ordenamento jurídico, bem como a garantia de satisfação: ordenamento efetivo é aquele em que a lei vigente é espontaneamente cumprida por corresponder à consciência jurídica ou em que sua atuação se dá coercitivamente, mediante a substituição da atuação do descumpridor da norma jurídica pela força do Estado (BEDAQUE, 2006, p. 17).

A Economia, por seu turno, também estuda o comportamento humano, não para regulá-lo, mas sim para compreender como o sujeito racional realiza suas escolhas em ambientes de recursos escassos. O ramo da economia que cuida da tomada de decisões individuais ou de grupos menores de indivíduos é a Microeconomia. Para avaliar essa relação 
entre meios escassos e fins rivais, os modelos econômicos partem da suposição de que os atores sociais sempre buscam maximizar seus interesses (COOTER; ULEN, 2016, p. 27).

Nessa senda, faz-se imperiosa rápida explanação acerca de alguns fundamentos econômicos com vistas a preparar o terreno para o debate da matéria. Ao tomarem decisões, os agentes acabam realizando escolhas conflitantes (tradeoffs), estabelecendo preferências entre objetivos. Para que as melhores decisões possam ser tomadas, é necessário que o agente tenha ciência das alternativas entre as quais deve escolher (MANKIW, 2009, p. 5). Disso se conclui que diante de tradeoffs, o agente racional deverá ponderar as vantagens e desvantagens de sua escolha, de modo a aferir os custos de oportunidade, entendidos como "qualquer coisa de que se tenha de abrir mão para obter algum item." (MANKIW, 2009, p. 6).

Com vistas a maximizar sua situação inicial, o tomador de decisões buscará implementar mudanças marginais, pequenos ajustes para melhorar seu nível de partida, o que implicará um custo adicional e também um benefício adicional. Dessa forma, o tomador de decisões continuará realizando pequenos incrementos enquanto o benefício marginal produzido continue superior ao custo marginal gerado (COOTER; ULEN, 2016, p. 41). Corolário disso é que o sujeito racional ajusta seu comportamento de acordo com a relação entre custos e benefícios, de forma que esse comportamento pode ser alterado em conformidade com os incentivos positivos ou negativos verificados (MANKIW, 2009, p. 7).

Nesse contexto, com apoio nas ferramentas da economia acima indicadas, é possível compreender os possíveis comportamentos dos indivíduos. Com efeito, em conformidade com os pressupostos lançados pela teoria da escolha racional os "agentes econômicos são racionais, respondem a incentivos e vivem em busca da maximização dos seus próprios interesses individuais." (MELMAN, 2019, p. 59 - grifos no original).

Há quem questione a compatibilidade da análise econômica com o direito, na medida em que promoveria a colonização do jurídico, de modo a substituir as questões fundamentais do direito, como justiça e segurança jurídica, por elementos da economia, como eficiência e maximização, o que poderia ocasionar uma desestruturação do sistema jurídico. Tais autores não negam que as ciências jurídica e econômica sempre possuíram pontos de contato e relação de complementariedade entre si, mas denunciam a prevalência da racionalidade econômica, pautada no custo-benefício, sobre o discurso jurídico, que serviria como mero instrumento do neoliberalismo global (MARCELLINO JR., 2010, p.94).

Denuncia José Reinaldo de Lima Lopes (2004, p. 8) que a racionalização pelo tipo base da economia traz o risco de um só pensamento, com o raciocínio econômico tomado 
como o único tipo de raciocínio aceitável, de modo que tudo aquilo que não se conformasse à lógica do custo-benefício seria tratado como um caso de irracionalidade, a ser excluído do sistema. A racionalidade se limitaria, assim, a apenas um dos sentidos da razão.

Uma das formas de os agentes econômicos realizarem esse desiderato de unificação dos sentidos da razão pela lógica do mercado seria por intermédio da inserção no discurso jurídico da categoria base econômica da eficiência:

Os teóricos da Análise Econômica do Direito, cientes das dificuldades e limitações
dos economistas para lidarem diretamente com questões legais, procuram
estabelecer uma nova racionalidade que justifique a sobreposição do econômico em
relação ao jurídico, e o fazem especialmente através da utilização do conceito ação
eficiente. [...] Tudo no Direito, de algum modo, estaria sempre ligado a este
parâmetro vinculador de análise, pois, sempre se estaria, mediante demandas
judiciais, à busca de compensações ou meios menos custosos de vida.
(MARCELLINO JR., 2010, p. 96 - grifos no original).

Existe mais de um conceito de eficiência em economia, mas a ideia básica é a de que um processo é eficiente quando não é possível produzir a mesma quantidade com menos recursos ou quando não há mais como aumentar a produção utilizando os mesmos insumos (COOTER; ULEN, 2016, p. 30). O conceito mais conhecido é o da eficiência alocativa ou eficiência de Pareto, que leva em consideração a satisfação das preferências dos indivíduos:

Decimos que una situación particular es eficiente en el sentido de Pareto o de la asignación si es imposible cambiarla para que por lo menos una persona mejore su situación (según sua propia estimación) sin empoerar la situación de otra persona (según su propia estimación). (COOTER; ULEN, 2016, p. 31).

As preocupações acima relatadas são bastante pertinentes, entretanto a interação entre direito e economia pode se dar em diversos planos, especialmente nos campos descritivo-positivo (ser) e prescritivo-normativo (dever-ser). Com minúcia, explicam Luiz Fux e Bruno Bodart (2019, p. 2):

A abordagem do Direito sob o prisma econômico pode assumir três diferentes
aspectos. O primeiro, denominado heurístico, preocupa-se com a identificação da
racionalidade que informa a existência de diferentes institutos jurídicos e lhes
confere coesão. [...] O segundo aspecto, chamado descritivo, é voltado à
determinação dos efeitos das normas jurídicas na sociedade, ou seja, investiga as
consequências decorrentes das normas legais em análise. [...] Esses dois primeiros
aspectos são por vezes reunidos sob a expressão "análise econômica do Direito
positiva". Finamente, o último aspecto é o de cunho normativo, que busca definir
quais normas jurídicas são desejáveis, comparando a eficiência a partir das
conclusões obtidas nos dois aspectos anteriores da análise.

A distinção é relevante porque a análise positiva está ligada ao estudo do impacto do direito sobre os fatos sociais concretos, para a correta compreensão da estrutura de incentivos e desincentivos subjacente às regras jurídicas. A análise positiva não busca, pois, mudar a 
realidade jurídica existente com vistas a alterar o comportamento social considerado “indesejado”, ao contrário da análise normativa (JORDÃO; ADAMI, 2007, p. 197).

A teoria funcionalista do direito também reconhece a existência de técnicas de encorajamento e de desencorajamento como meios de influenciar o comportamento social, conforme a função protetivo-repressiva ou promocional do ordenamento jurídico. A principal diferença entre tais ordens jurídicas está no tipo de conduta humana sob enfoque: no ordenamento repressivo o foco se dá sobre os comportamentos não desejados e as maneiras de combatê-los; ao passo que no promocional a atenção do ordenamento se volta aos comportamentos desejáveis e às formas de realizá-los (BOBBIO, 2007, p. 15).

Nessa senda, sustenta-se que a análise econômica normativa não teria por escopo nem deveria ser utilizada com vistas à fixação dos objetivos sociais a serem perseguidos pelo Direito, mas apenas como aconselhamento técnico quanto aos meios a serem adotados para se alcançar um fim previamente estipulado. Como explicam Jordão e Adami (2007, p. 198):

\begin{abstract}
A normatividade desta espécie de AED significa que as suas conclusões possuem natureza prescritiva, mas isto não implica a imposição do valor "eficiência econômica" sobre outros valores juridicamente protegidos. Note-se que a eficiência é quase sempre um valor-meio. Quaisquer valores juridicamente protegidos podem ser realizados com dispêndio excessivo ou ótimo dos recursos escassos, bem como através de vias eficazes ou ineficazes. A AED normativa, na maioria dos casos, prescreverá a adoção dos meios mais baratos ou mais eficazes para a realização de finalidades sociais de qualquer ordem. Isto significa que o recurso à eficiência não visa a promover a substituição de outros valores, mas a garantir-lhes a realização.
\end{abstract}

Por conseguinte, a interação entre o direito e a economia, também denominada de movimento Law and Economics, pode ser sinteticamente explanada pela seguinte passagem de Ivo T. Gico Jr. (2010, p. 8):

O direito é, de uma perspectiva mais objetiva, a arte de regular o comportamento humano. A economia, por sua vez, é a ciência que estuda como o ser humano toma decisões e se comporta em um mundo de recursos escassos e suas conseqüências. A Análise Econômica do Direito, portanto, é o campo do conhecimento humano que tem por objetivo empregar os variados ferramentais teóricos e empíricos econômicos e das ciências afins para expandir a compreensão e o alcance do direito e aperfeiçoar o desenvolvimento, a aplicação e a avaliação de normas jurídicas, principalmente com relação às suas conseqüências.

Estabelecidas essas correlações entre Direito e Economia, passa-se a investigar a disciplina específica da Análise Econômica da Litigância, em que o ferramental acima é utilizado para entender os motivos que levam as pessoas a ingressarem com demandas, as razões pelas quais outras pessoas preferem não submeter suas pretensões ao Judiciário, renunciando aos direitos dos quais acreditam ser titulares, bem como outras questões correlatas ao exercício do direito de ação e do acesso à justiça, sob a ótica econômica. 


\section{ANÁLISE ECONÔMICA DA LITIGÂNCIA}

Para que o agente privado tenha incentivos suficientes para ingressar com uma ação em juízo, é necessário que os custos de demandar sejam inferiores aos benefícios esperados pelo acionante, quais sejam, resultado potencial de acordos ou julgamentos no processo judicial (KAPLOW; SHAVELL, 2002, p. 1722). Ocorre que nos custos privados da litigância são consideradas apenas as despesas próprias do autor, o qual não computa em sua análise os custos do réu ou do Estado com a demanda ajuizada. Dessa forma, os custos privados pela utilização do sistema judicial serão necessariamente inferiores aos custos sociais envolvidos (KAPLOW; SHAVELL, 2002, p. 1723).

De outra parte, o benefício social da demanda envolve o efeito dissuasório (deterrent effect) no comportamento dos infratores e, em alguns casos, a compensação das vítimas, além da formação de jurisprudência sobre a matéria (KAPLOW; SHAVELL, 2002, p. 1725). Já o benefício privado se limita a melhoria experimentada pelo autor, pouco importando a ocorrência do "deterrent" ou a possibilidade do estabelecimento de precedentes, de modo que em muitas demandas não há qualquer benefício social. Essa divergência entre o privado e o social causa um desequilíbrio nos níveis de litigância, exigindo atuação estatal: seja para brecar a litigância excessiva, sobretaxando ou barrando certas demandas; seja para combater a escassez de demandas, incentivando o acesso ao judiciário por meio de subsídios econômicos ${ }^{2}$ (PATRÍCIO, 2005, p. 49).

A despeito do modelo de litigância acima, nem sempre o demandante pauta sua conduta de acordo com a racionalidade econômica, de modo que algumas ações são ajuizadas mesmo quando os custos da litigância são superiores ao benefício esperado: são as denominadas demandas de valor esperado negativo. Trata-se de gênero que engloba as demandas frívolas (em que as chances de êxito são remotas ou inexistentes) e aquelas ações em que a vitória é quase certa, mas o retorno financeiro esperado é inexpressivo ${ }^{3}$ (FUX; BODART, 2019, p. 87).

\footnotetext{
${ }^{2}$ Importante frisar que SHAVELL construiu sua teoria partindo da premissa que a finalidade primordial do processo judicial seria o desincentivo à prática de novos atos ilícitos (deterrent). Considerando apenas esse incremento (ou não) do efeito dissuasório é que o autor classifica as ações como socialmente convenientes ou não. Trata-se de modelo que não considera a efetividade dos direitos numa sociedade democrática, parecendo não se amoldar às normas constitucionais, em especial ao art. $5^{\circ}$, caput e $\S 1^{\circ}$.

${ }^{3}$ Entretanto, como explicam JORDÃO e ADAMI (2007, p. 214), o constituinte originário considerou que a possibilidade de se levar uma demanda ao Judiciário, por si só, já representaria um benefício social, como se constata da dicção do art. $5^{\circ}$, XXXV. Essa valorização do direito de ação em si é entendida como manifestação do exercício da cidadania, como respeito ao pertencimento de cidadão, de respeito ao Estado de Direito.
} 
A par disso, outra classificação de interesse é aquela que divide os sujeitos processuais em litigante habitual e litigante eventual. Da constatação do senso comum de que os agentes que possuem mais recursos financeiros e melhor organização teriam vantagem na hora de litigar, Marc Galanter (1974, p. 97) elaborou a distinção entre os atores sociais que raramente se utilizam do sistema de justiça (One-Shotters ou OS) e aqueles que - em razão do porte, recursos e estado de direito - têm muitas possibilidades de recorrerem às cortes (Repeat Players ou RP). Tais categorias são assim explicadas pelo referido autor:

Let us refine our notion of the RP into an "ideal type" if you will-a unit which has had and anticipates repeated litigation, which has low stakes in the outcome of any one case, and which has the resources to pursue its long-run interests [...] An OS, on the other hand, is a unit whose claims are too large (relative to his size) or too small (relative to the cost of remedies) to be managed routinely and rationally. (GALANTER, 1974, p. 98).

Os conceitos econômicos até aqui expostos servirão de base para a compreensão dos motivos do excesso de litigância e de como essa situação prejudica o funcionamento do Poder Judiciário como um todo, bem assim das maneiras como essa conjuntura pode ser combatida da melhor forma possível. No próximo capítulo os modelos econômicos serão utilizados para analisar os métodos empregados pelo legislador de 2017 para reduzir os níveis de litigiosidade da Justiça do Trabalho.

\section{O ACESSO AO JUDICIÁRIO TRABALHISTA PÓS-REFORMA DE 2017 SOB O PRISMA DA ANÁLISE ECONÔMICA DO DIREITO}

Desde a consolidação do Direito do Trabalho no Brasil, verificou-se a inaptidão do processo civil comum para disciplinar a tutela dos direitos trabalhistas, razão pela qual houve uma preocupação com a formulação de normas processuais próprias, quando da edição da Consolidação das Leis do Trabalho (CLT). É que o Direito Processual do Trabalho está umbilicalmente ligado ao direito material a que visa tutelar, devendo ser orientado por seus princípios básicos, inclusive pelo Princípio da Proteção (CHAVES, 2012, p. 64).

Fruto do Princípio da Isonomia em sua vertente material, o Princípio da Proteção no processo decorre da observação fática de que a parte economicamente mais forte na relação de direito substancial também trará à disputa judicial sua superioridade técnica, econômica e de poder. Daí a necessidade da correção desse desequilíbrio também na via instrumental, de modo que são asseguradas ao litigante mais fraco (trabalhador) prerrogativas processuais compensatórias, tanto em face de sua hipossuficiência econômica quanto no tocante a sua dificuldade de produzir provas (SCHIAVI, 2012, p. 101). 
Por conta disso, o processo do trabalho sempre foi regido por normas que visavam facilitar o acesso ao Judiciário pelo trabalhador hipossuficiente, como o pagamento das custas ao final (como regra), o princípio da gratuidade, o jus postulandi das partes e a inexistência de honorários de sucumbência (em regra). Note-se que, muito embora a CLT tenha sido editada em 1943, as normas do processo trabalhista estavam em perfeita harmonia com o posicionamento defendido por Mauro Cappelletti e Bryant Garth (2015, p. 93-94), em famoso estudo realizado na década de 1960 sobre o acesso à justiça, caracterizando-se pela informalidade, custos reduzidos, ampla liberdade na direção do processo pelo juiz e celeridade. Ocorre que a partir da divulgação do Projeto de Florença, evidenciou-se um aumento substancial da procura por prestação jurisdicional, numa explosão de litigância conforme divulgado pela mídia e elites políticas.

Essa sobrecarga do Poder Judiciário é facilmente constatada pela análise do Relatório Justiça em Números do Conselho Nacional de Justiça (CNJ), publicado no mesmo ano em que editada a Lei da Reforma Trabalhista. Com efeito, no ano-base 2016 ingressaram 29,4 milhões de processos e foram baixados 29,4 milhões, restando ao final do referido ano 79,7 milhões de processos aguardando solução. Trata-se de retenção bastante considerável: "mesmo que o Poder Judiciário fosse paralisado sem o ingresso de novas demandas e mantida a produtividade dos magistrados e dos servidores, seriam necessários aproximadamente 2 anos e 8 meses de trabalho para zerar o estoque.” (2017, p. 67).

Em virtude dessas constatações, corrente significativa da doutrina considera que o Judiciário é comparável a um recurso rival e de uso comum, de modo que os jurisdicionados tendem a utilizá-lo além do que precisam. No dizer de Fernanda Becker (2018, p. 76):

[...] a causa desse congestionamento é explicada pela "Tragédia dos Comuns", pelo
que, em resumo, múltiplos agentes têm acesso ilimitado a recursos finitos, o que
induz o comportamento inevitável de utilização imoderada, uma vez que é
impossível saber se os demais cooperarão e utilizarão apenas o necessário.
Como exemplo da Tragédia dos Comuns, tem-se os Juizados Especiais: são gratuitos
(não cobram custas judiciais), não se requer a presença de advogados até certo valor,
não há honorários sucumbenciais em caso de derrota e seu procedimento é
amplamente simplificado, com vistas a ampliar o acesso e reduzir a carga do
Judiciário, atendendo a uma demanda reprimida. Não por outra razão, estudos do
Conselho da Justiça Federal, do Centro de Estudos Judiciários (2003) e da Secretaria
de Reforma do Judiciário do Ministério da Justiça (2005) apontam para o
congestionamento dos juizados nos mesmos moldes da justiça comum.

Uma das formas de combater esse congestionamento ocasionado pelo uso excessivo da máquina judicial foi o endurecimento das regras para concessão da gratuidade da justiça e o aumento das despesas judiciais, caminho trilhado pela Lei n. 13.467/2017. 
A universalidade do acesso à justiça foi identificada pelo legislador reformista como a grande responsável pela situação crítica do judiciário trabalhista. Haveria uma desproporcionalidade, um descompasso entre os custos do atual modelo e os benefícios trazidos à sociedade. Para os que advogam essa tese, tendo em vista se tratar de direito fundamental, o acesso à justiça poderia e deveria sofrer restrições, desde que respeitado o núcleo essencial do direito, sem obstar o exercício legítimo do direito de ação (MELMAN, 2019, p. 166-167).

Não foi levado em conta naquela realidade, as eventualidades do não cumprimento das normas materiais de trabalho e a litigiosidade contida que este comportamento empresarial pode trazer, nem tampouco o grande número de trabalhos informais existentes no país, que inexoravelmente proporcionam uma busca pela efetividade do Direito pela via judicial.

Dessa forma, como os recursos públicos são finitos, o desequilíbrio econômicofinanceiro verificado no Poder Judiciário acaba impedindo o Estado de realizar outros serviços públicos fundamentais, que igualmente necessitam de expressivas quantias. Para Silveira (2020, p. 54), essa situação caracterizaria uma inconstitucionalidade relacionada às consequências da estrutura normativa, pois o acesso à justiça em vigor seria desproporcional em seu aspecto econômico-financeiro, afrontando o princípio constitucional da eficiência.

Essa é, em síntese, a fundamentação teórica de ordem juseconômica que alicerçou o enrijecimento das regras de acesso ao judiciário trabalhista, implementado por meio da Lei n. 13.467/17. Aliás, do exame do Parecer do Relator ao Projeto de Lei n. 6.787/2016 (que resultou na Reforma Trabalhista), verifica-se a invocação de argumentos econômicos e consequencialistas, no sentido de que o estímulo ao ajuizamento de ações trabalhistas decorre da litigância sem risco (PRL n. 1/2017, p. 67).

Como resultado, regras que concretizavam no âmbito trabalhista a primeira onda de acesso à justiça foram profundamente modificadas, de modo a substituir o princípio da gratuidade antes vigente pelo critério da causalidade da sucumbência, com vistas a redistribuir entre as partes a responsabilidade pelas despesas processuais. A título exemplificativo, citemse as seguintes novidades referentes ao beneficiário da justiça gratuita: cobrança de custas processuais no caso de arquivamento da reclamação, sendo seu pagamento condição para propositura de nova demanda (Art. 844, $\S \S 2^{\circ}$ e $3^{\circ}$ ); necessidade de comprovação da insuficiência de recursos como condição para a obtenção da gratuidade da justiça (Art. 790, § $4^{\circ}$ ); responsabilização pelos honorários periciais em caso de sucumbência, na hipótese de 
obtido em juízo créditos capazes de suportar a despesa, ainda que em outro processo (Art. 790-B, $\S 4^{\circ}$ ); e inaplicabilidade da suspensão de exigibilidade das obrigações referentes aos honorários advocatícios sucumbenciais, caso obtido em juízo créditos capazes de suportar a despesa, ainda que em outro processo (Art. 791-A, § $4^{\circ}$ ).

O debate acerca da constitucionalidade desses novos dispositivos legais foi levado ao E. Supremo Tribunal Federal, por meio de ação direta de inconstitucionalidade n. 5.766/DF, proposta pela Procuradoria-Geral da República. Embora a referida ADI não tenha sido julgada até o presente momento, em julgamento anterior do E.STF é possível verificar uma sinalização para o tema, em que se decidiu pela constitucionalidade da Lei n. 11.495/2007 que dispôs sobre exigência de depósito prévio, em percentual superior ao estabelecido no processo comum, para o ajuizamento de ação rescisória na Justiça do Trabalho. Cuida-se da ADI 3.995, cuja ementa do acórdão é a seguinte:

DIREITO CONSTITUCIONAL E PROCESSUAL DO TRABALHO. AÇÃO
DIRETA DE INCONSTITUCIONALIDADE. DEPÓSITO PRÉVIO EM AÇÃO
RESCISÓRIA. ACESSO À JUSTIÇA E AMPLA DEFESA.
PROPORCIONALIDADE. 1. As normas processuais podem e devem criar uma
estrutura de incentivos e desincentivos que seja compatível com os limites de
litigiosidade que a sociedade comporta. A sobreutilização do Judiciário congestiona
o serviço, compromete a celeridade e a qualidade da prestação da tutela
jurisdicional, incentiva demandas oportunistas e prejudica a efetividade e a
credibilidade das instituições judiciais. Afeta, em última análise, o próprio direito
constitucional de acesso à Justiça. 2. Dessa forma, é constitucional o depósito
prévio no ajuizamento de ação rescisória como mecanismo legítimo de desincentivo
ao ajuizamento de demandas ou de pedidos rescisórios aventureiros. Não há
violação a direitos fundamentais, mas simples acomodação com outros valores
constitucionalmente relevantes, como à tutela judicial efetiva, célere e de qualidade.
O depósito no percentual de 20\% sobre o valor da causa não representa uma medida
demasiadamente onerosa, guardando razoabilidade e proporcionalidade. [ADI 3.995,
rel. min. Roberto Barroso, j. $18-12-2018, \mathrm{P}$, DJE de $1^{\circ}-3-2019$ - grifos acrescidos].

Por conseguinte, não se nega a possibilidade, em certas hipóteses, da limitação do acesso ao Judiciário com vistas à promoção de outro interesse constitucionalmente assegurado. A análise econômica do direito pode servir, inclusive, como suporte teórico apto a fundamentar a necessidade e a adequação da medida restritiva imposta pelo legislador.

Entretanto, existem vários fatores que afetam os níveis de litigância da sociedade, sendo as despesas do acionante com o processo apenas um deles. Essa não é, portanto, a única forma de controlar quantitativamente a litigância (exagerada ou insuficiente), como esclarecem Luiz Fux e Bruno Bodart (2019, p. 41-42):

Havendo excesso de litigância, as seguintes políticas públicas podem ser adotadas para aliviar o problema: impor um limite de gastos em litigância; criar um tributo sobre a litigância; aumentar as custas judiciais; ou mesmo proibir o ajuizamento de ações judiciais sobre certas matérias. Por outro lado, se a litigância for socialmente 
insuficiente, os remédios regulatórios poderiam ser a diminuição das custas judiciais ou outra forma de subsídio para demandas.

Ademais, a redução dos níveis de litigância pura e simplesmente não pode ser o único objetivo perseguido pelo legislador reformista, até porque a jurisdição tem diversos escopos (no plural) a serem desempenhados mediante seu exercício. Sobre o tema, lapidares são as palavras de Cândido R. Dinamarco (2008, p. 137):

Existe realmente um feixe de objetivos a serem alcançados mediante a atividade que se convencionou chamar jurisdicional e que se situam no campo propriamente jurídico (atuação da vontade do direito substancial), no campo social (pacificação com justiça; educação para a consciência dos próprios direitos e respeito aos alheios) e no político (afirmação do poder estatal; participação democrática; preservação do valor liberdade $[\ldots]$

Nesse contexto, o escopo social-pedagógico da jurisdição é de suma importância para a explicação da teoria da litigância concebida por Steven Shavell, que considera como objetivo principal do processo civil a capacidade de desencorajar (deterrent effect) comportamentos que não trazem benefício social. Em outras palavras, as normas processuais devem ter por objetivo maximizar a promoção do cumprimento espontâneo das obrigações (MELMAN, 2019, p. 136). Como instrumento do direito material do trabalho, o processo está a serviço da conservação da integridade da ordem jurídica trabalhista, de modo que suas normas - de uma forma geral - devem promover a efetividade das regras estatais de proteção do trabalho. Assim, a primeira preocupação do legislador processual é incentivar o cumprimento espontâneo das obrigações laborais, ficando a redução dos custos sociais da litigância condicionada à consecução daquele objetivo. Como enfatizam Jordão e Adami:

\footnotetext{
Não se discorda que o sistema processual deva ser voltado a minimizar os custos para a sociedade, mas essa não pode ser a única pauta para avaliar o número de processos na sociedade. Sob essa ótica, no Brasil, bastaria elevar abruptamente as taxas processuais, além de impor o sistema "americano", pelo qual cada uma das partes arca com seus próprios custos. Isso seria o bastante para excluir boa parte da população do acesso judicial, e conseqüentemente reduzir os custos sociais, pois haveria um número menor de processos e maior recolhimento de taxas. Entretanto, esse cenário não se coaduna com as demais finalidades a serem perseguidas pelo Estado. (2007, p. 214).
}

A racionalidade econômica tende a maximizar seus benefícios, de modo que se não houver incentivos para investir no cumprimento da legislação trabalhista, v.g. na redução dos riscos inerentes ao trabalho, a tendência é que o empregador transfira esses custos para a sociedade (externalidade negativa) de forma mediata e imediatamente para o empregado.

Disso resulta a constatação - de certa forma negligenciada nos estudos sobre a temática - de que a maior rigidez ou flexibilidade da regulação do mercado de trabalho deve ser aferida necessariamente em conjunto com as práticas sociais verificadas naquele Estado: 
“o sistema de regulação do trabalho de determinado país pode ser muito detalhado e rígido em termos formais, mas muito flexível na prática, simplesmente porque os empregadores podem escolher não cumprir o que a lei prescreve." (CARDOSO; LAGE, 2005, p. 452).

Nesse contexto, sob a ótica da gestão empresarial, pode-se afirmar que a escolha pelo cumprimento ou não da legislação de proteção ao trabalho é tomada tendo em vista o critério de racionalidade da maximização de benefícios e minimização de prejuízos, de modo que na hipótese de "o empregador considerar que os custos trabalhistas são muito altos, ele pode decidir correr o risco de não pagá-los.”(CARDOSO; LAGE, 2005, p. 453). Assim, em conformidade com os dados apresentados em estudo dos referidos autores, é possível inferir que o comportamento estratégico por parte do empresariado brasileiro é pelo descumprimento generalizado da legislação do trabalho (CARDOSO; LAGE, 2005, p. 454).

Ressalte-se que a executabilidade do contrato de trabalho é diminuída em razão da morosidade do judiciário, o que funciona como incentivo ao descumprimento contratual. Por conseguinte, se o livre acesso do trabalhador ao judiciário já não é suficiente para garantir o cumprimento do contrato, mesmo que de forma geral após o contrato de trabalho, visto que não existem condições efetivas de garantias no emprego após a propositura de reclamação trabalhista, com a edição de norma que torna o acesso ao judiciário para o trabalhador bastante dificultado, a tendência segundo a racionalidade econômica é que o descumprimento generalizado da legislação do trabalho se torne o padrão de comportamento a ser seguido no mundo empresarial, inserindo-se nos riscos do empreendimento, em desrespeito a um conteúdo mínimo legal de subsistência do trabalhador com dignidade e em desacordo com a função social da propriedade. Em todos os casos, em desrespeito às normas constitucionais, em especial às previstas nos arts. $1^{\circ}$, III e IV, $3^{\circ}, 5^{\circ}$, XXII e $7^{\circ}$, além de toda estrutura trabalhista estabelecida pela Organização Internacional do Trabalho (OIT) em sua agenda de trabalho decente, em observância aos Objetivos de Desenvolvimento Sustentável estabelecidos pela Organização das Nações Unidas (ONU), em especial o de número 8.

Com efeito, de acordo com a agenda 2030 de desenvolvimento sustentável da ONU (2015), o crescimento econômico sustentado, inclusivo e sustentável está vinculado à proteção dos direitos trabalhistas e à promoção de ambientes de trabalho seguros e do trabalho decente. Este último aspecto foi formalizado pela OIT (2006) no final da década de 1990 e engloba quatro objetivos: 1) respeito aos Princípios e Direitos Fundamentais no Trabalho previstos na Declaração da OIT de 1998; 2) a promoção do emprego produtivo e de qualidade; 3) a ampliação da proteção social; e 4) o fortalecimento do diálogo social. 
Dessa forma, ao invés de servir como garantia de efetivação do direito material do trabalho, a novel legislação processual acaba por dificultar a exigibilidade das normas de proteção ao trabalho e, em sucessivo, desestimular o cumprimento espontâneo das obrigações laborais. Pode-se, portanto, concluir que essa alteração ampliou o desequilíbrio entre os litigantes, que o processo tentava minimizar por intermédio da paridade de armas, considerando que não houve qualquer desestímulo direcionado aos grandes litigantes.

Os Repeat Players (conhecidos no Brasil como litigantes habituais) dispõem de diversas condições vantajosas em relação aos participantes eventuais quando do embate em juízo, decorrentes do serviço jurídico, dos aparelhos institucionais e das regras jurídicas. Quanto às vantagens ligadas ao tipo de parte (litigante habitual ou eventual), destacam-se as seguintes: 1) economia de escala; 2) como tem uma longa série de casos, não está preocupado em minimizar a probabilidade de perda daquele processo individual em disputa, podendo correr mais riscos pensando em maximizar seus ganhos no total dos casos; 3) podem despender recursos para influenciar a modificação das regras jurídicas de direito material que lhes sejam desfavoráveis, por meio de lobby; 4) igualmente têm capacidade para alterar as regras de direito processual, não para o caso em disputa, mas para os futuros, até porque tudo que puder favorecer o resultado das futuras ações vale à pena (GALANTER, 1974, p. 100).

Pois bem. É inconteste que o baixo valor das custas processuais tem relação direta com o elevado número de ações. Tanto isso é verdade que as estatísticas da Justiça do Trabalho revelam uma grande redução no número de reclamações trabalhistas ajuizadas após a vigência da Lei n. 13.467/2017. De acordo com Relatórios da Coordenadoria de Estatística e Pesquisa do C.TST, as Varas do Trabalho receberam 2.756.156 processos no ano de 2016; 2.647.450 processos de janeiro a dezembro de 2017 e 1.748 .074 processos no ano de 2018, o que revela uma redução de 34\% no número de novas ações entre os anos de 2017 e 2018 (TST, 2017, p. 5; TST, 2018, p. 2).

Todavia, o congestionamento que atinge o Poder Judiciário como um todo não decorre apenas do ajuizamento de grande número de novas ações. Nesse contexto, ao se optar pelo incremento das despesas com a litigância, como medida para reduzir a litigiosidade, deve-se fazê-lo em todas as suas fases processuais, desestimulando também o manejo de recursos. Após discorrer sobre os incentivos privados para se ingressar em juízo - no sentido de que os custos do processo sejam inferiores às expectativas da partes em relação ao resultado da sentença -, bem como sobre a influência dos custos em prosseguir com a demanda, Miguel Carlos Teixeira Patrício (2005, p. 51) vaticina: 
[...] o fenómeno do excesso de litigância é também, muitas vezes, o resultado de uma excessiva utilização dos recursos. Um dos factores maiores que justifica o recurso é o da correcção do erro. A esta luz, regular os custos do recurso poderia impedir os recursos frívolos.

Recurso frívolo pode ser entendido como aquele em que o recorrente tem pouca ou nenhuma chance de sucesso em alterar a decisão judicial. Trata-se de medida incentivada pela reduzida despesa com o acesso à fase recursal. Por essa razão é que MELMAN (2019, p. 140) defende que todo aquele que se beneficia dos baixos custos de litigar (não apenas o beneficiário da justiça gratuita), transferindo externalidades negativas à sociedade, tem seu acesso aos tribunais subsidiado.

Por conseguinte, concentrar os esforços no combate aos abusos de beneficiários da gratuidade de justiça é insuficiente para modificar a situação atual, pois ataca apenas parte do problema, sendo imperioso reconhecer as características específicas dos grandes litigantes com vistas a reduzir o excesso de litigância: como o fato de os Repeat Players não serem dissuadidos pelas elevadas taxas de condenação judicial e continuarem com as mesmas práticas ilícitas (MELMAN, 2019, p. 140).

No caso da reforma trabalhista, curiosamente, não houve qualquer investimento no sentido de penalizar a litigância habitual ou mesmo de dificultar a interposição de recursos frívolos. Ao contrário, o réu-empregador em situação de insuficiência econômica teve seus custos reduzidos pela metade ou totalmente isentados no tocante ao recolhimento do depósito recursal (Art. 899, $\S \S 9^{\circ}$ e 10 , e $855-\mathrm{A}, \S 1^{\circ}$, II, da CLT) ${ }^{4}$. O tratamento dado ao réuempregador, nesse aspecto, deduz-se que foi anti-isonômico e subverteu a lógica de valores do processo do trabalho, consistindo em verdadeiro incentivo à litigância na fase recursal.

Há um evidente descompasso, no pertinente ao instituto da gratuidade da justiça, entre o acesso à justiça e o acesso ao duplo grau de jurisdição, na medida em que as restrições impostas ao acionante com vistas a limitar a "litigância excessiva" não foram repetidas em relação ao réu-recorrente, que conta com facilitado acesso ao segundo grau de jurisdição.

\footnotetext{
${ }^{4}$ Art. 899 - Os recursos serão interpostos por simples petição e terão efeito meramente devolutivo, salvo as exceções previstas neste Título, permitida a execução provisória até a penhora.

[...]

$\S 9^{\circ}$ O valor do depósito recursal será reduzido pela metade para entidades sem fins lucrativos, empregadores domésticos, microempreendedores individuais, microempresas e empresas de pequeno porte.

$\S 10$. São isentos do depósito recursal os beneficiários da justiça gratuita, as entidades filantrópicas e as empresas em recuperação judicial.

Art. 855-A. Aplica-se ao processo do trabalho o incidente de desconsideração da personalidade jurídica previsto nos arts. 133 a 137 da Lei ${ }^{\circ} 13.105$, de 16 de março de 2015 - Código de Processo Civil.

$\S 1^{\circ}$ Da decisão interlocutória que acolher ou rejeitar o incidente:

[...]

II - na fase de execução, cabe agravo de petição, independentemente de garantia do juízo;
} 
Some-se a esse acesso módico e irrestrito a todas as instâncias recursais o fato de que os juros que remuneram as ações trabalhistas são bastante inferiores aos juros de mercado (bancários), acabando por funcionar como incentivo ao descumprimento das obrigações. Como esclarece Ivo T. Gico Jr. (2020, p. 232 e 236), a remuneração das demandas por meio de juros de mora adequados poderia reduzir os efeitos deletérios da demora na entrega da prestação jurisdicional, uma vez que essa morosidade provoca uma seleção adversa entre aqueles que são titulares de direito e aqueles que buscam o Judiciário apenas para procrastinar o adimplemento: "Quanto mais demorado for para se obter a prestação jurisdicional, menor o valor presente do direito. No limite, um Judiciário arbitrariamente lento destrói o próprio direito pleiteado", como é possível ser verificado com recente decisão da suprema corte, adiante tratada.

No caso da Justiça do Trabalho, estudo realizado pela Fundação Getúlio Vargas (FGV) indicou que litigar vale mais a pena que fazer acordo, mesmo diante de valores relativamente pequenos e das baixas chances de vitória dos empregadores (SALAMA; YEUNG; CARLOTTI, 2019, p. 2). Um fato apontado como impactante no nível de litigância é a taxa de juros dos débitos trabalhistas, que se reflete no custo de oportunidade de devedores e credores trabalhistas: 1) para os devedores, a taxa é inferior a esse custo, sendo mais vantajoso investir ou quitar outras dívidas; 2) para os credores, a taxa é superior a da poupança, correspondendo a um bom investimento aguardar o término da execução (SALAMA; YEUNG; CARLOTTI, 2019, p. 6)

De fato, há de se concordar com as conclusões da pesquisa no sentido de que o montante da taxa de juros irá pressionar uma das partes a realizar acordo: se a taxa for muito alta, o devedor terá interesse em conciliar o mais rápido possível; ao passo que no caso de juros de mora muito baixos, será o credor quem terá a iniciativa de firmar o acordo, no caso dos créditos sociais, como os decorrentes da demanda trabalhista, vilipendiando a sua dignidade duas vezes. Uma quando trabalha e não tem o cumprimento do pacta sunt servanda e a segunda, quando precisa transacionar o mínimo reconhecido em juízo para poder ter acesso ao crédito de subsistência, como se tem teleologicamente previsto na norma do art. $7^{\circ}$, IV, da Constituição.

Para o devedor-empregador, adimplir as obrigações trabalhistas apenas em juízo, vários anos após o vencimento da dívida, afigura-se bastante vantajoso: “O custo financeiro de todo seu procedimento (correção monetária e custos judiciais) é menos oneroso do que a obtenção de um simples financiamento diante das altas taxas de juros praticadas no Brasil." 
(JORDÃO; ADAMI, 2007, p. 215). Trata-se de confirmação empírica de constatação do senso comum, no sentido de que protelar a dívida no judiciário é financeiramente mais vantajoso ao devedor trabalhista.

Todavia, no julgamento conjunto das ADC 58, ADC 59, ADI 5.867 e ADI 6.021, o E. STF ampliou o abismo entre o índice de correção do débito trabalhista e os custos de oportunidade do empregador, como se constata da ementa do acórdão:

Ações diretas de inconstitucionalidade e ações declaratórias de constitucionalidade. 2. Art. 879, $\S 7^{\circ}$, e art. 899, $\S 4^{\circ}$, da CLT, na redação dada pela Lei 13. 467, de 2017. Art. 39, caput e $\$ 1^{\circ}$, da Lei 8.177 de 1991. 3. Constitucionalidade dos índices de correção dos depósitos recurais e dos débitos trabalhistas na justiça do trabalho. 4. Política de correção monetária e tabelamento de juros. Institucionalização da Taxa Referencial - TR como política de desindexação da economia. Combate histórico a processos inflacionários. Risco de constitucionalização de normas financeiras e do sistema monetário nacional. 5. TR como índice de correção monetária. Inconstitucionalidade. Precedentes do STF. 6. Apelo ao legislador. Aplicação, até que sobrevenha solução legislativa, dos mesmos índices de correção monetária e de juros vigentes para as hipóteses de condenações cíveis em geral: IPCA-E na fase pré-judicial e SELIC a partir da citação. 7. Ações diretas de inconstitucionalidade e ações declaratórias de constitucionalidade julgadas parcialmente procedentes, para conferir interpretação conforme à Constituição ao art. $879, \S 7^{\circ}$, e ao art. $899, \S^{\circ}$, da CLT, na redação dada pela Lei 13.467, de 2017. 8. Modulação de efeitos.

(ADI 5867, Relator(a): GILMAR MENDES, Tribunal Pleno, julgado em 18/12/2020, PROCESSO ELETRÔNICO DJe-063 PUBLIC 07-04-2021)

Isso significa que os juros de mora trabalhistas, anteriormente apurados à taxa de $\mathbf{1 \%}$ ao mês (pouco mais de $12 \%$ anuais), foram reduzidos ao patamar de $\mathbf{2 \%}$ ao ano, de acordo com a cotação atual da taxa SELIC, fixada em agosto de 2020. O E. STF partiu da premissa de que a correção dos créditos trabalhistas era extremamente vantajosa para os trabalhadores. Trata-se de conclusão que ignora, segundo o que se tem no dia a dia, a realidade das relações de trabalho no que concerne ao desequilíbrio de forças entre os contratantes, ademais, com a devida vênia, do confronto com toda a estrutura de equiparação formal entre os sujeitos da relação de trabalho estabelecida na disciplina trabalhista, aproximando cada vez mais as relações jurídicas de trabalho às de direito comum.

Como já explicava Adam Smith no Século XVIII, para garantirem sua subsistência os trabalhadores acabavam por se submeter às condições oferecidas pelos patrões, que se utilizavam da natural situação de vantagem nas disputas que surgiam: "a maior parte dos obreiros não subsistiria por si uma semana ou um mês, e raros seriam os que poderiam se manter sem emprego por um ano.” (2014, p. 108).

Assim, diferentemente do que ocorre com um grande litigante, o trabalhador não teria condições de ponderar custos de oportunidade e tirar proveito da morosidade judicial, em prejuízo de seu sustento e de sua família. A premissa utilizada pelo E. STF mostra-se, 
portanto, como acima indicado, equivocada. Isso porque consoante aparato epistemológico da Análise Econômica da Litigância, os juros legais deveriam ser os mais próximos dos juros de mercado para que se obtenha o efeito dissuasório. Trata-se de tema relevante que exige investigação mais aprofundada, escapando ao propósito do presente trabalho.

Por conseguinte, o excesso de litigância verificado em todo o Poder Judiciário (e não apenas na Justiça do Trabalho) é resultado de uma série de variáveis: falta de incentivo ao cumprimento espontâneo das obrigações, o que tem reflexo no grau de civilidade da sociedade, a inexistência do efeito dissuasório da litigância, juros legais muito inferiores aos de mercado, baixos custos de litigar (principalmente para os litigantes habituais), além da própria morosidade do serviço judicial. O enfrentamento de apenas uma dessas variáveis, eleita como a "responsável" pelo congestionamento do Poder Judiciário, não resolverá o problema. Uma atuação irrefletida poderá, aliás, agravá-lo.

Nesse contexto, a atuação legislativa centrada apenas na maior onerosidade do processo do trabalho se mostra insuficiente, impondo-se a consideração dos demais aspectos que influenciam a litigiosidade nas relações entre o capital e o trabalho. Somente dessa forma será possível a manutenção da integridade da ordem jurídica trabalhista, simultaneamente à redução na taxa de congestionamento da Justiça do Trabalho, em todas as suas instâncias.

\section{CONCLUSÃO}

Em conformidade com a teoria funcionalista do direito, o ordenamento jurídico se vale de técnicas de encorajamento e de técnicas de desencorajamento como meios de influenciar o comportamento social. Por seu turno, a escola Law and Economics parte do pressuposto de que as normas jurídicas são como um preço, de modo que o agente dotado de racionalidade responde a esses incentivos e desincentivos normativos de acordo com o modelo econômico de maximização da utilidade.

Considerando que o Poder Judiciário brasileiro enfrenta problema de sobreutilização, com altos índices de congestionamento em todas as suas instâncias, as premissas fixadas pela Análise Econômica do Direito podem servir como suporte teórico apto a fundamentar medidas legislativas que conduzam à redução da litigiosidade a patamares compatíveis com o nível de conflituosidade suportado pela sociedade.

Existem alguns fatores que podem afetar os níveis de litigância da sociedade (para cima ou para baixo), sendo o montante das despesas do acionante com o processo apenas um 
deles. Ademais, é importante ressaltar que a redução dos níveis de litigância pura e simplesmente não pode ser o único objetivo perseguido pelo legislador processual, até porque a jurisdição tem diversos escopos, dentre os quais o escopo social-pedagógico. Em outras palavras, as normas processuais devem ter por objetivo principal maximizar a promoção do cumprimento espontâneo das obrigações de direito material.

Entretanto, a novel legislação processual trabalhista acabou por dificultar o acesso ao Judiciário, que restou mais oneroso ao trabalhador, fato que prejudica na mesma proporção a exigibilidade das normas de proteção ao trabalho. Isso termina por se refletir nos custos de oportunidade do devedor trabalhista, tornando mais vantajoso ao empregador deixar para adimplir as obrigações trabalhistas em juízo.

Tal se dá porque o trabalhador médio terá receio de suportar os novos riscos da litigância, de modo que muitos deles deixarão de demandar e renunciarão aos direitos dos quais acreditam ser titulares. Assim, a redução do número de novas ações distribuídas após a vigência da referida lei configura benefício apenas aparente, considerando que o cumprimento espontâneo das obrigações laborais acaba, em última análise, sendo desestimulado pela recente legislação, face às dificuldades adicionais de acesso que foram impostas.

Ocorre que, como instrumento do direito material do trabalho, o processo está a serviço da conservação da integridade da ordem jurídica trabalhista, de modo que suas normas - de uma forma geral - devem promover a efetividade das regras estatais de proteção do trabalho. Assim, a preocupação basilar do legislador processual é incentivar o cumprimento espontâneo das obrigações laborais, ficando a redução dos custos sociais da litigância condicionada à consecução daquele objetivo.

Nesse contexto, a atuação legislativa centrada apenas na maior onerosidade do processo do trabalho se mostra insuficiente à consecução desse escopo, impondo-se a consideração de todos os aspectos que influenciam a litigiosidade nas relações entre o capital e o trabalho. Somente dessa forma será possível a manutenção da integridade da ordem jurídica trabalhista, simultaneamente à genuína redução na taxa de congestionamento da Justiça do Trabalho, em todas as suas instâncias.

\section{REFERÊNCIAS}

BECKER, Fernanda Elisabeth Nöthen. Custas judiciais e justiça gratuita como fator de (in)eficiência da prestação jurisdicional do Poder Judiciário de Santa Catarina. Dissertação (Mestrado profissional) - Centro de Ciências Jurídicas, Universidade Federal de Santa Catarina, Santa Catarina, 2018. 
BEDAQUE, José Roberto dos Santos. Direito e processo: influência do direito material sobre o processo. 4. ed. rev. e amp. São Paulo: Malheiros, 2006.

BOBBIO, Norberto. Da estrutura à função: novos estudos de teoria do direito. Tradução Daniela Beccaccia Versiani. Revisão Técnica Orlando Seixas Bechara e Renata Nagamine. Barueri: Manole, 2007.

BRASIL. Câmara dos Deputados. Comissão Especial destinada a proferir parecer ao Projeto de Lei $n^{\circ}$ 6787, de 2016, do Poder Executivo. Parecer do Relator n. 1/2017. Brasília: Câmara dos Deputados, 12 abr. 2017. Disponível em: https://www.camara.leg.br/proposicoes Web/fichadetramitacao?idProposicao=2129284. Acesso em: 26 fev. 2020.

BRASIL. Conselho Nacional de Justiça. Justiça em Números 2017: ano-base 2016. Brasília: CNJ, 2017. Disponível em: https://www.cnj.jus.br/pesquisas-judiciarias/justica-em-numeros/. Acesso em: 01 jan. 2021.

BRASIL. Tribunal Superior do Trabalho. Coordenadoria de Estatística e Pesquisa. Movimentação processual das varas do trabalho: Ano de 2017. Brasília: Tribunal Superior do Trabalho, 31 dez. 2017. Disponível em: http://www.tst.jus.br/web/estatistica/vt/ movimentacao-processual. Acesso em: 27 abr. 2020.

BRASIL. Tribunal Superior do Trabalho. Coordenadoria de Estatística e Pesquisa. Movimentação processual das varas do trabalho: Ano de 2018. Brasília: Tribunal Superior do Trabalho, 31 dez. 2018. Disponível em: http://www.tst.jus.br/web/estatistica/vt/ movimentacao-processual. Acesso em: 27 abr. 2020.

CAPPELLETTI, Mauro; GARTH, Bryant. Acesso à justiça. Tradução Ellen Gracie Northfleet. Porto Alegre: Sergio Antonio Fabris, 2015.

CARDOSO, Adalberto; LAGE, Telma. A Inspeção do Trabalho no Brasil. DADOS Revista de Ciências Sociais, Rio de Janeiro: Universidade do Estado do Rio de Janeiro, Vol. 48, n. 3, p. 451-490, jul./set. 2005.

CHAVES, Luciano Athayde. Interpretação, aplicação e integração do direito processual do trabalho. In: CHAVES, Luciano Athayde (org.). Curso de processo do trabalho. 2. ed. São Paulo: LTr, 2012. p. 41-89.

COOTER, Robert D.; ULEN, Thomas. Derecho y economía. Tradução Eduardo L. Suárez. Tradução e revisão da nova edição María Teresa Franco González. Cidade do México: Fondo de Cultura Económica, 2016. E-book.

DINAMARCO, Cândido Rangel. A instrumentalidade do processo. 13. ed. rev. e atual. São Paulo: Malheiros, 2008.

FUX, Luiz; BODART, Bruno. Processo civil \& análise econômica. Rio de Janeiro: Forense, 2019. 
GALANTER, Marc. Why the "Haves" Come out Ahead: Speculations on the Limits of Legal Change. Law \&SocietyReview, Vol. 9, n. 1, p. 95-160, 1974. Disponível em: https://www.jstor.org/stable/3053023?seq=1. Acesso em: 14 fev. 2020.

GICO JR., Ivo Teixeira. Metodologia e epistemologia da análise econômica do direito. Economic Analysis of Law Review, Brasília: Universa, v. 1, n. 1, p. 7-33, jan./jun. 2010.

GICO JR., Ivo Teixeira. Análise econômica do processo civil. Indaiatuba: Editora Foco, 2020 .

JORDÃO, Eduardo Ferreira; ADAMI, Mateus Piva. Steven Shavell e o preço do processo: notas para uma análise econômica do direito processual. In: JORDÃO, Eduardo Ferreira; DIDIER JR., Fredie (coord.). Teoria do processo: panorama doutrinário mundial. Salvador: Juspodivm, 2007. p. 189-218.

KAPLOW, Louis; SHAVELL, Steven. Economic analysis of law. Handbook of Public Economics, 2002, vol. 3, p. 1661-1784. Disponível em: http://www.law.harvard.edu/faculty/ shavell/pdf/99_Economic_analysis_of_law.pdf. Acesso em: 24 abr. 2020.

LOPES, José Reinaldo de Lima. Raciocínio Jurídico e Economia. Revista de Direito Público da Economia, Belo Horizonte, v. 2, n.8, p. 137-170, 2004.

MANKIW, N. Gregory. Introdução à economia. Tradução Allan Vidigal Hastings. São Paulo: Cengage Learning, 2009.

MARCELLINO Jr., Julio Cesar. O movimento Law and Economics e a eficiência como critério de justiça: incompatibilidades entre direito, economia e democracia. Unisul de Fato e de Direito: Revista jurídica da Universidade do Sul de Santa Catarina. Palhoça: Editora Unisul, v. 1, n. 1, p. 93-102, 2010.

MELMAN, Ana Carolina. Análise econômica no processo civil brasileiro: limites e possibilidades. Rio de Janeiro: Lumen Juris, 2019.

ORGANIZAÇÃO DAS NAÇÕES UNIDAS. Os Objetivos de Desenvolvimento Sustentável no Brasil. [Brasília]: ONU, 2015. Disponível em: https://brasil.un.org/ptbr/sdgs/8. Acesso em: 16 abr. 2021.

ORGANIZAÇÃO INTERNACIONAL DO TRABALHO. Trabalho Decente. OIT. [Brasília]: OIT, [ca. 2006]. Disponível em: https://www.ilo.org/brasilia/temas/trabalhodecente/lang--pt/index.htm. Acesso em: 16 abr. 2021.

PATRÍCIO, Miguel Carlos Teixeira. Análise económica da litigância. Coimbra: Almedina, 2005.

SALAMA, Bruno Meyerhof; YEUNG, Luciana L; CARLOTTI, Danilo. Quando Litigar Vale Mais a Pena do que Fazer Acordo: os grandes litigantes na Justiça 
Trabalhista. FGV Working Paper - Série: O Judiciário Destrinchado pelo 'Big Data'. Rio de Janeiro: FGV, 2019.

SCHIAVI, Mauro. Nova leitura dos princípios do direito processual do trabalho. Tese (Doutorado em Direito), Pontifícia Universidade Católica de São Paulo, São Paulo, 2012.

SILVEIRA, Ricardo Geraldo Rezende. Acesso à justiça: o direito fundamental em um ambiente de recursos escassos. São Paulo: Almedina, 2020.

SMITH, Adam. Compêndio riqueza das nações. Tradução Bento da Silva Lisboa. São Paulo: Hunter Books, 2014. 